\title{
The CHLA/ABSC Social Media Interest Group: the Creation of the Best Practices Social Media Portal
}

\author{
Dean Giustini, Laurie Blanchard, Judy Inglis, Marie-Marthe Gagnon, and members \\ of the Social Media Interest Group
}

\section{Introduction}

Over the past few years, health librarians around the world have become involved in a range of exciting and innovative projects using social media [1-5]. In Canada, apart from speaking about a social media project at a conference or publishing a paper in JCHLA/JABSC, health librarians have lacked informal spaces to share their experiences and success stories in using these tools.

To address this problem, a small group of CHLA/ABSC members - Laurie Blanchard (acting as Board liaison), Judy Inglis, and Dean Giustini - began discussing ways in which health librarians could learn more about or become more comfortable with the use of social medial tools in their daily information practice. Thus, the concept of a Social Media Interest Group was born, and terms of reference were drafted. After the terms of reference were accepted by the CHLA/ABSC Board, the group began to recruit new members through our personal social media contacts and the CANMEDLIB listserv. The interest group held its first face-to-face meeting in conjunction with the CHLA/ABSC Annual Conference in Hamilton in 2012.

Throughout this formative period for the Social Media Interest Group, Board members continued to emphasize the importance of creating a space to share best practices and provide value for members. Based on these discussions the interest group has focused its energies on creating a portal that can be easily accessed on the CHLA/ABSC website.

\section{The aim of a social media portal}

The aim of the CHLA/ABSC portal is to provide an easily accessible space to share ideas, program descriptions, resources, and best practices. Currently, there are several projects described on the portal. Are you interested in seeing how other health librarians are using social tools? Do you have a project you'd like to share? Health librarians considering the use of a specific social media tool can learn a lot by examining these projects and by talking to the librarian who used them. The platform is designed to provide a vehicle for interaction, virtual networking, and information exchange, without the constraints associated with the formal (and sometimes intimidating) venues such as writing a paper or presenting at a conference. It is anticipated that use of the platform may also provide some contributors with the support and encouragement needed to consider publishing and presenting their work.

\section{What does the social media portal contain?}

- The portal, which can be found at http://www.chla-absc. ca/search_best_practices, includes a searchable database of social media projects and initiatives of interest to Canadian health librarians.

- Future goals for the portal are to include links to guidelines, policies, training objects, and other resources related to the development, implementation, and evaluation of social media tools and applications.

- Contributions to the database may include (but are not limited to) descriptions of the use of social media tools and resources in a health library and (or) information services setting, tools or methodologies used for evaluating social media, checklists, "lessons learned", evaluations of exemplary information tools, and portals of interest to health librarians

- The portal has both French and English interfaces; contributions can be made in either official language.

\section{Official launch at the 2013 Conference}

The portal had its official launch at the 2013 Saskatoon Conference. Laurie Blanchard provided an overview of the portal during the AGM, and Pat Lee and Dean Giustini presented audience members with a social media portal bookmark and invited everyone to contribute to the portal, make use of portal content, and provide suggestions and feedback for enhancements. The initial response to the portal has been positive - the best practices database now contains 10 descriptions of tools, programs, and initiatives.

\section{Marketing and promotion}

As well as more traditional approaches, the Social Media Interest Group will be using a variety of social media approaches to market, promote, and evaluate the use and usefulness of the portal. Watch for a more detailed discussion of these approaches in a future column. 


\section{How can you get involved?}

Please help develop and promote the portal by taking a few minutes to:

- contribute to the database and tell us about your initiatives and experiences;

- find projects and information relevant to your needs; and

- tweet and blog, tell your colleagues about the portal.

Need more information, or have suggestions for content, features, or enhancements for the portal? Contact us at: socialmedia@chla-absc.ca

In the meantime, you can follow some of our activities on Twitter by using the hashtags \#somedport \#chlaabsc

\section{Members of the Social Media Interest Group}

Laurie Blanchard, Judy Inglis, Dean Giustini, Pat Lee, Marie-Marthe Gagnon, Teodora Constantinescu, Kathryn Ranjit, Angela Osterreicher, Helen Lee Robertson, and Michelle Swab

\section{References}

1. Cuddy C, Graham J, Morton-Owens EG. Implementing Twitter in a health sciences library. Med Ref Serv $Q$. 2010;29(4):320-30. doi:10.1080/02763869.2010.518915.

2. Jayaraman S. Selecting an IM aggregator for a virtual reference service at UT Southwestern Medical Center Library. J Hosp Librarian. 2009;9(4):433-38. doi:10.1080/1532326090 323308 .

3. McGowan J, Hogg W, Salzwedel D. A rapid evidence-based service by librarians provided information to answer primary care clinical questions. Health Info Libr J. 2010;27(1):11-21. doi:10.1111/j.1471-1842.2009.00861.x.

4. Read K, Giustini D. Social media for health care managers: creating a workshop in collaboration with the UBC Centre for Health Care Management. JCHLA/JABSC. 2011;32(3):15763. doi:10.5596/c11-047.

5. Spring H. If you cannot beat them, join them! Using health 2.0 and popular Internet applications to improve information literacy. Health Info Libr J. 2011;28(2):148-51. doi:10.1111/ j.1471-1842.2011.00934.x. 